\title{
LA DIMENSIÓN TEMPORAL DE LAS TRAYECTORIAS DE LOS INMIGRANTES ANDINOS EN LA CIUDAD DE MADRID
}

\author{
THE TEMPORAL DIMENSION OF THE TRAJECTORIES OF ANDEAN \\ IMMIGRANTS IN THE CITY OF MADRID
}

\author{
Juan José Ruiz Blázquez \\ Universidad Complutense, Madrid. España/Spain \\ ruizblazquezx@yahoo.es
}

Recibido/Received: 30/06/2013

Aceptado/Accepted: 05/10/2013

\section{RESUMEN}

Este artículo es el resumen de una investigación acerca de cómo una determinada concepción temporal de la existencia genera un tipo de subjetividad e identidad. Estos dos conceptos nos han servido para comprender los procesos de vulnerabilidad social de los emigrantes andinos, especialmente ecuatorianos, en la ciudad de Madrid. Para acercarnos a sus trayectorias personales y sociales hemos producido material biográfico mediante lo que hemos denominado narraciones de vida, relatos fruto de entrevistas en profundidad, para así desentrañar cómo el tiempo y el espacio son variables fundamentales para entender la mentalidad y el imaginario cultural de los inmigrantes, en definitiva, sus trayectorias de adaptación al país de destino.

\section{PALABRAS CLAVE}

Tiempo, espacio, subjetividad, vulnerabilidad.

\section{SUMARIO}

1. Introducción. 2. Marco teórico. 3. Metodología. 4. Hipótesis de partida. 5. Las mujeres, los varones y el tiempo. 6. La infancia. 7. La juventud. 8. Decisión de emigrar. 9. El azote del reloj. 10. Consideraciones finales. Bibliografía.

\begin{abstract}
This article is a summary of an investigation into how a particular temporal conception of existence generates a kind of subjectivity and identity. These two concepts have helped us to understand the processes of social vulnerability Andean immigrants, especially Ecuadorians in the city of Madrid. To get closer to their personal and social trajectories have biographical material produced by what I call life narratives, stories result of in-depth, so well unravel how time and space are key variables to understand the mentality and cultural imaginary immigrants, their adaptation paths to the destination country.
\end{abstract}

\section{KEYWORDS}

Time, space, subjectivity, vulnerability.

\section{CONTENTS}

1. Introduction. 2. Theoretical Framework. 3. Methodology. 4. Hypothesis. 5. Women, men and time. 5.1. Childhood. 5.2. Youth. 6. Decision to migrate. 7. The scourge of the clock. 8. Final considerations. References. 


\section{INTRODUCCIÓN}

Lejos de ser trivial o puro parámetro que mide o sitúa a las cosas sin incorporarse a ellas, el tiempo es central. El tiempo es un recurso de la acción y un revelador de las determinaciones más hondas de los fenómenos sociales ¿Cómo no prestar entonces atención a esta dimensión tan humana y darla por presupuesta sin más? ¿Cómo no dirigir nuestra mirada a las distintas formas de vivir y relacionarse con el tiempo? Si queremos comprender la trayectorias personales y sociales de los emigrantes ecuatorianos de la ciudad de Madrid hay que atender a las variables espacio-temporales, es decir, hay que objetivar las relaciones que mantienen con el pasado, el presente y el futuro, saber cuál es el relato de sus biografías, comprender y explicar el sentido vivido de sus trayectorias. El tiempo como institución tiene una base social, y por tanto puede ser tematizado por la sociología, pues la concepción del tiempo con sus elementos integradores y normativos pertenece al mismo proceso de socialización. Ha sido necesario, por tanto, hablar con ellos en las dos orillas del océano, haciendo un recorrido a través de los distintos espacios de socialización por los que han transitado. He intentado confrontar la temporalidad de Madrid con la de Quito para comprender las relaciones que se establecen entre lo espaciotemporal y determinados tipo de subjetividad e identidad. Distinguiremos cómo viven y experimentan las dimensiones temporales y espaciales las mujeres, por un lado, y los varones, por otro, pues presumimos configuran una manera de ser distinta en ambos sexos, habilitando una nueva vía para comprender y explicar los procesos de vulnerabilidad social.

\section{MARCO TEÓRICO}

Al intentar aproximarnos al tiempo nos asalta la duda sobre qué tipo de tiempo estamos hablando, si del tiempo cósmico, del tiempo de la conciencia, del tiempo del reloj, del tiempo social o de cualquier otro tiempo. Ramón Ramos ha mostrado que la sociología, en sus diversos intentos, ha tratado de acotar y tipificar un tiempo propio, el tiempo social, que sólo es plausible si lo tomamos como una metáfora cómoda y expresiva, no confundiendo tiempo y proceso, es decir, no se trataría de un tiempo o un conjunto de tiempos, sino del complejo conglomerado formado por los aspectos temporales de la realidad social (Ramos, 1992). "El tiempo intencional y el tiempo de la sucesión serían las dos dimensiones de un tiempo único, tanto si las ciencias sociales abordan el estudio sociológico de sus manifestaciones sociales como si se trata de la construcción teorética en ciencia social" (Ramos, 1997:12-13).

Las categorías de espacio y de tiempo, que Kant define como las categorías a priori de la sensibilidad, son en realidad categorías sociales. Para Durkheim "las categorías son el esqueleto mismo de la inteligencia" (Durkheim, 1992:8), representaciones colectivas con cierto carácter coercitivo en las que los sujetos somos socializados. "La experiencia del tiempo es un caso entre otros muchos de actitudes sociales o estructuras sociales de la personalidad de los individuos" (Elías, 1989:158), por lo que el sentido del tiempo, del espacio y de lo realizable, aunque personal en una mínima parte, está determinado socialmente. Con todo, el tiempo no sólo es la rememoración subjetiva de experiencias pasadas de acuerdo al orden en que sucedieron antes, sino también un marco abstracto que responde a exigencias comunes de comunicación con los demás para que sea posible la observación y el entendimiento de los hechos. 
La sociedad, y cada sociedad, es ante todo institución de una temporalidad implícita, con su correspondiente manera de hacer el tiempo y de darle existencia, temporalidad efectiva que conlleva un modo de hacer que se impone a todos los individuos y que es a su vez una manera de ser (Castoriadis, 1989). Por tanto, comprender una sociedad es inseparable de la descripción de su temporalidad dominante. Es imprescindible y necesario algún esquema temporal inteligible que no diverja en cuanto a su significado y a sus fronteras, que los grupos e individuos estén orientados lo más posible a un mismo horizonte temporal. En el primer proceso de socialización, ya desde la más temprana infancia, aprendemos a relacionarnos con el tiempo de una determinada manera. Toda socialización es en gran parte socialización anticipatoria, por lo que hay que llenar este proceso con contenidos de futuro desde el principio, aún más, "lo colectivo y lo individual se articulan en el proceso de socialización para que sea posible que todos los miembros de una sociedad asimilen los objetivos y metas parta el futuro" (Iglesia, 2006:192-193). Para que esta asimilación se lleve a cabo de la manera más completa los sujetos necesitan predecir las acciones de los otros para que puedan confiarse a que se confirmen sus expectativas con las acciones y las expectativas de las otras personas. Max Weber señala que "las acciones sociales deben descansar plena y exclusivamente en la probabilidad de que se actuará socialmente en una forma (sentido) indicable" (Weber, 1987:21). "El estado social, como una versión consecuente del estado democrático, ha descansado en el reconocimiento mutuo de los ciudadanos como seres semejantes y dignos de confianza" (Sotelo, 2010:391), por lo que la desconfianza y la incertidumbre que acarrea la disolución de los vínculos sociales obligan a una tentativa de recomposición mediante la comunicación y el acercamiento a las experiencias de los demás para crear o aumentar nuestros horizontes, a modo de estela que nos trace el sendero para hacer frente a lo impredecible del destino. La pobreza de las experiencias que propician las sociedades urbanas bien puede formar parte de la problemática de la cuestión social, tal como señala Richard Sennett (1975)

\section{METODOLOGÍA}

La inmigración está hecha fundamentalmente de tiempo, sentido, afectos, olvidos, esperanzas, sueños y esperas, materiales no muy distintos de los que está hecho el universo social, y que la sociología trata de desentrañar. El estudio de la inmigración nos descubre la sociedad de acogida, los mecanismos a través de los cuales tenemos noticia del otro, cómo se piensan a sí mismos los emigrantes y con qué conceptos. Acercarnos a la sociología de la inmigración es también indagar acerca de la identidad de la sociedad de inmigración a través de quien no es ella misma. Detrás de cada teorización acerca de lo que es la inmigración existe una manera de acercarse a ella, lo que se traduce en un opción metodológica, una concepción determinada de la sociedad, y una propuesta de cómo deben de ser las relaciones sociales.

Los trabajos de la Escuela de Chicago producidos entre 1910 y 1940, de los que esta investigación es deudora, forman parte constitutiva del patrimonio sociológico en el estudio de las migraciones. Las investigaciones que desarrollaron William Thomas, Robert Park, y sus discípulos, tuvieron como contexto histórico un mundo en transformación bajo los efectos de la industrialización, la urbanización y la migración. Los problemas sociales causados por el desarrollo del capitalismo en los Estados Unidos tenían una expectativa de 
solución científica bajo la guía de la recién nacida disciplina sociológica. La novedad de los sociólogos de Chicago fue centrarse en los procesos de subjetivación, es decir, cómo los inmigrantes vivían su proceso de adaptación o inadaptación en sociedades muy distintas a sus comunidades de origen, regidas por pautas culturales y valores morales muy distantes. Fue W. Thomas quién inició el tránsito del estudio de la cuestión social a los problemas sociales, quien convirtió el punto de vista de los actores sociales en una base para la explicación de los mismos fenómenos sociales. Thomas hizo caso omiso de cualquier consideración de tipo histórico y se situó más cerca de la estela de Dilthey que la de Weber. La sociología que practicaron los sociólogos de Chicago fue a la vez una réplica y un complemento del conductismo psicológico. Si las situaciones son percibidas como reales, son reales en sus consecuencias, proclama el teorema de Thomas. La naturaleza y la sociedad son como el sujeto las percibe, y no como las ve el científico, así que éste debe ponerse en la posición de los sujetos investigados, buscando la explicación de la conducta personal en la experiencia del individuo que actúa. El efecto de un fenómeno social depende, además de su contenido empírico, del punto de vista adoptado por el individuo o el grupo hacia ese fenómeno, es decir, del significado atribuido a ese fenómeno. A pesar de su contacto con la inmediatez del mundo social, los sociólogos de la denominada Escuela de Chicago desplazaron progresivamente la cuestión social a la cuestión racial, debido a los problemas generados por la diversidad cultural en una ciudad en plena expansión demográfica e industrial. "El peaje que tuvo que pagar la sociología fue mantener el silencio sobre la génesis y el desarrollo del capitalismo y disolver la cuestión social por la cuestión racial, no sintiendo los sociólogos norteamericanos la necesidad de disciplinar el capitalismo a través de la creación del Estado social" (Uría, 2004). Este énfasis en la dimensión subjetiva de la conducta social dejó de lado interrogantes tales como la dimensión ideológica de los procesos sociales y los mecanismos inconscientes de la conducta, convirtiendo la sociedad en una colección de problemas encargando a la sociología de analizarlos en situación, por lo que los sociólogos de Chicago renunciaban a entrar en el debate que enfrentó a la ciencia social socialista con la economía política, renunciando a abordar la naturaleza del liberalismo y el capitalismo. Los sociólogos de Chicago renunciaron a afrontar las diversas formas de explotación, precisamente cuando Estados Unidos estaba emergiendo como potencia hegemónica a nivel mundial. Pero el hecho de no asumir la sociología marxista como una vulgata, el hecho de optar por el reformismo, no dejó sin embargo de estimular su imaginación sociológica.

Desde el punto de vista metodológico hemos intentado acercarnos a la temporalidad de la población andina de Madrid recurriendo a materiales biográficos mediante la realización de nueve entrevistas focalizadas, denominando a nuestro método narraciones de vida, para diferenciarlas de las historias de vida. Y es que más que intentar reconstruir todo un denso itinerario biográfico nuestro objetivo ha sido intentar establecer una relación entre biografía y contexto histórico para establecer una inteligibilidad longitudinal de la emigración andina en la Comunidad de Madrid. Es importante señalar la distinción porque no vamos en búsqueda de toda la historia de cada uno de los entrevistados, sino que nos centramos en una parte de sus experiencias vividas, en momentos determinados de su existencia, en nuestro caso, esa parte de sus vidas que posibilitan la comprensión de los motivos que les indujeron a emigrar y que tienen que ver con la dimensión temporal de la vida social y personal, además de cómo han interiorizado este hecho en la sociedad madrileña. Además de restituir el pasado histórico o biográfico, hemos estado atentos a las dimensiones temporalizadoras y temporalizantes de la experiencia subjetiva, es decir, a aquellos discursos que connotan posiciones subjetivas que no se sintetizan en imágenes de 
un yo, sino que se expresan en modos temporales: dejar de ser, llegar a ser, lo que no pudo ser, lo que ha llegado a ser, lo que hubiera podido ser, etc., (Pazos, 2004). En concreto, hemos entrevistado a cinco mujeres y a cuatro varones en Madrid. Por otra parte, en Quito, hemos entrevistado a un varón y a una mujer que emigró del campo a la capital de Ecuador.

En este texto aparecerán en cursiva sólo fragmentos de las entrevistas realizadas en Madrid, La edad de las mujeres entrevistadas está comprendida entre los veinte y cinco hasta los sesenta y tres años, al igual que la de los varones. Las mujeres están identificadas con: Mujer 1 (ecuatoriana, lugar de origen urbano, estudios medios), Mujer 2 (ecuatoriana, lugar de origen rural, estudios superiores), Mujer 3 (Ecuatoriana, lugar de origen semiurbano, estudios primarios), Mujer 4 (peruana, lugar de origen rural, estudios primarios) y Mujer 5 (peruana, lugar de origen urbano, estudios medios). Respecto a los varones entrevistados en Quito, dos son ecuatorianos, uno es peruano y el otro es colombiano. Los varones están identificados con: Varón 1 (ecuatoriano, lugar de origen rural, estudios medios), Varón 2 (ecuatoriano, lugar de origen semiurbano, estudios medios), Varón 3 (colombiano, lugar de origen urbano, estudios superiores), y Varón 4 (peruano, lugar de origen urbano, estudios superiores).

\section{HIPÓTESIS DE PARTIDA}

De las diversas marginaciones de que son objeto los emigrantes andinos, especialmente ecuatorianos, abunda una que supone una rémora para lleva una existencia plena y llena de sentido, y que no es otra que la imposición de un tiempo extraño, capitalista, impidiendo que se reconozcan a sí mismos, mostrándose el tiempo impotente para cohesionar a individuos y a grupos. Una de las dificultades más penosas que lleva consigo la emigración es que no permite a los emigrantes pensar ni pensarse a sí mismos al no disponer de marcos espaciales y temporales apropiados, algo que afecta a sus oportunidades para actuar y decidir. Partimos de la hipótesis de que una determinada manera de hacer, experimentar e interiorizar el tiempo puede conducir a procesos de vulnerabilidad social, entendiendo este concepto como un enfriamiento del vínculo social en el que todos los miembros dejan de pertenecer a un mismo conjunto (Castel,1995).

\section{LAS MUJERES, LOS VARONES Y EL TIEMPO}

\subsection{La infancia}

Ser varón o ser mujer no es indiferente a los distintos significados atribuidos al tiempo, y por tanto a su vivencia y a su experimentación. Las mujeres son muy pronto destinadas a servir a los demás, mientras que los varones tienen mayores oportunidades de aprender mayor autonomía. El trabajo y las responsabilidades asumidas desde muy temprana edad las obligan a mantener una relación con la familia y el mundo que las rodea desde la practicidad material, quedando poco margen para idealizaciones sentimentales como en el caso de los varones, al recaer sobre ellas las duras exigencias de la vida doméstica. No tienen tiempo para el juego y siempre están ocupadas en quehaceres ajenos a la niñez. Esto explica que para ellas se pierda muy rápidamente el recuerdo de la infancia por ser su vivencia muy corta. La infancia para los varones, por el contrario, es más larga, y se 
muestra como un universo lleno de sorpresas donde existe la posibilidad de jugar y experimentar con la naturaleza. Manejan una concepción más imaginaria de esta época de la vida. La familia y la naturaleza son percibidas como espacios míticos donde no ocurren acontecimientos capaces de trastocar ese orden imaginario al que son tan propensos en sus relatos. Para los varones la imagen adquiere tal potencia evocadora, sobre todo de su infancia, que mitifica aún más un mundo sin conflictos. Al contrario de lo que les ocurre a las mujeres, el espacio de la infancia es idealizado e inmaterializado.

Mi hermana nos hacía la comida, pero no la importaba. Como todo era para todos, nadie se molestaba por hacer algo por los demás (Varón 1).

En las mujeres, sin embargo, predomina la palabra como espacio de negociación y de conflicto, por esa facilidad para relacionar los acontecimientos, haciendo un ejercicio de reflexión sobre lo que les ha sucedido, y teniendo por tanto una concepción más realista y dura de los avatares de su existencia, pues para ellas el maltrato familiar ha marcado profundamente sus vidas.

Mi madre veía que sufría mucho, no así los varones, porque ellos se dedicaban a exigir para tener lo que ellos quisieran (Mujer 1).

Tan importante es la distinción de género, que el tiempo y la identidad de los varones en sus países de origen tiene que ver fundamentalmente con la mujeres, pues ésta es quien preserva y mantiene las tradiciones y normas familiares en momentos de crisis, como cuando muere o falta el padre o la madre, o ambos.

En el mundo rural los problemas de herencia y las envidias familiares son de tal calibre que en muchas ocasiones se convertirán en los detonantes que carguen la espoleta del tiempo, empezando, sobre todo para los varones, a tomar conciencia de la irreversibilidad de los acontecimientos. La cuestión racial es otra de las constantes en la vida de las mujeres y los varones ya desde la infancia, contribuyendo a crear subjetividades racializadas, impidiendo ir más allá de los marcos espaciales y temporales impuestos.

Mi padre decía que sus nuevos hijos eran más guapos, que tenían los ojos más claritos. Mi hermano dijo que la única venganza nuestra era estudiar, demostrándole que los del pueblito tal vamos a salir adelante (Mujer 2)

\subsection{La juventud}

Cuando lleguen a la juventud, mujeres y varones poseen conceptos, imágenes, ideas y formas de relacionar los hechos de manera distinta. Empiezan, literalmente, a habitar el mundo de manera diferente. Las mujeres buscando el amor romántico. Soñando la búsqueda de un varón que les saque de la rutina para empezar a construir un futuro. Siempre quise conocer a un hombre que me quisiese para quedarme toda la vida con él (Mujer 1). En este momento empieza a labrarse el conflicto, sobre todo con las madres, que consideran que el amor hay que ponerlo en un segundo plano, priorizando la búsqueda de un varón que les evite pasar por las mismas penurias económicas y la escasez material que han tenido que soportar.

Mi papá estaba atento de hacerme casar con un señor riquísimo propietario de varias haciendas y que tenía cincuenta años. ¡Es que mi papá estaba más joven que este señor! (Mujer 3).

Este desacuerdo reforzará aún más la construcción de un tiempo interior, buscando denodadamente el amor en el interior de sus corazones, pues en el mundo exterior habita la 
desconfianza y acechan peligros insondables, tales son las experiencias negativas que han tenido con sus parejas, recluyéndose en un mundo propio de mujeres.

He tenido la oportunidad de conseguir novio, pero no he querido. Mejor es estar solita y no pensar en nadie (Mujer 3).

A pesar de los sinsabores que el amor les reporta, empiezan a tener confianza en sí mismas y deciden emigrar, dejando atrás unas circunstancias vitales no del todo gratas. Los varones, mientras tanto, han salido de su mundo imaginario, instalados en el reino del conflicto que supone habitar el espacio público, alejados ya de la protección familiar. Los cambios que protagonizan y en los que se ven envueltos, optar por las diferentes alternativas que la elección les plantea, casa mal con esa idealización de un mundo estable y ordenado. El tiempo lineal al que se ven expuestos cuando salen del espacio familiar supone asumir responsabilidades, incompatibles con la socialización en un tiempo circular donde todo se repite, en el que la responsabilidad se ve disminuida a favor de un "dejar pasar el tiempo", donde no hay un comienzo ni un final.

No entiendo por qué todo cambió. Perdí el trabajo; perdí el negocio; perdí a mi mujer y recuperé mi trabajo. Pero ya nada era igual. No entiendo por qué todo cambia una vez. que...No sé (Varón 1).

Las relaciones con las mujeres, los noviazgos que protagonizan, están sujetos a las consecuencias de esta forma particular de relacionarse con el tiempo.

Estaba sin camino en ese tiempo, sin saber qué hacer, o sea, no tenía sentido nada (Varón 1). Las mujeres para los varones son como una especie de salvavidas que les facilita salir del mundo del vicio y de las juergas, en suma, de la mala vida. Necesitan mujeres que no bailen, ni beban, ni fumen, en definitiva, que no tengan vicio alguno.

Era una chica de casa. Con su ayuda dejé ese mundo (Varón 1).

\section{DECISIÓN DE EMIGRAR}

Cuando las mujeres han emigrado, los varones se quedarán en sus países de origen totalmente desconcertados, perdidos, sin rumbo. De uno en uno empezaron a venirse todos y cuando me doy cuenta aquí ya había despedido a todos y me quedé solo (Varón 1). El predominio de la responsabilidad individual, muy relacionada con la decisión de emigrar de las mujeres, está muy vinculado a la escasez material porque hay que superarla sea como sea. Emigrar es una oportunidad, un acontecimiento que irrumpirá en sus vidas y que asumirán desde la más absoluta individualidad y convencimiento propio para romper con ese tiempo impuesto y apenas elegido.

En mi pueblo no había vida, todo el tiempo lo mismo. ¿A qué aspirabas allí? Quería conocer otras maneras de vivir (Mujer 3).

En el caso de las mujeres existe una tensión entre lo comunitario y lo individual que se resolverá en la toma de una decisión radical: emigrar. Dejan atrás a la familia, hijos e hijas incluidos, aunque ello suponga el reproche familiar y del entorno más cercano. Salir fuera de sus comunidades y emigrar a la ciudad en algunas ocasiones, antes de partir al extranjero, supone embarcarse en un nueva vida facilitada por un tipo de habitus adquirido ya desde la primera infancia, un estilo de vida que descansa en una particular destreza del 
manejo del tiempo y los contratiempos, administrando el tiempo de manera prodigiosa entre las diversas actividades, haciendo frente a lo imprevisible, controlando lo azaroso, creando y aprovechando nuevas o viejas oportunidades, todo ello aderezado de una confianza inexpugnable en sí mismas pues poseen unas energías prácticamente inagotables.

Mis hijos saben decirme "mamita ya no trabaje, deje". "Ya no trabaje", dicen. "Ya deje, ya deje, qué saca trabajando, para qué" dicen. "Si papá ya trabaja, para qué trabaja”. Pero es que... iY qué hago yo! Todo el día no voy a estar así, ¿qué hago yo sin hacer nada? No puedo sin hacer nada, a mí me falta tiempo para hacer las cosas (Mujer 3).

Cuando emigren del campo a la ciudad, antes de partir al extranjero, han adquirido un aprendizaje del mundo urbano, han aprendido a elegir una serie de prioridades que están ligadas de manera indisociable a una asignación del tiempo determinada, sobre todo en lo que se refiere a la planificación horaria de sus actividades.

En Quito me levantaba a las siete de la mañana para asistir a clase. Terminaba a las diez y cuarenta y cinco $u$ once. Tenía toda la tarde libre pero no conocía a nadie. Mi hermano me marcó un plan de trabajo. Me dijo: "Usted va a hacer esto; estos serán sus amigos; estudie lo que le ha indicado el profesor; investigue; busque en la biblioteca; y luego ya sabe lo que tiene que hacer, ir a su casa. En tu cabeza se te tiene que meter esto: si le gusta estudiar, estudiar, si le gusta trabajar, a trabajar. Y a saber administrar. Y si quiere trabajar y estudiar mucho mejor todavía”. Y esa fue la gran oportunidad (Mujer 2).

Plantearse la decisión de emigrar permite soltar lastre de la pesada carga de una vida monótona y sin alicientes. Es algo así como lanzarse desde un barco a la mar sin antes haber aprendido a nadar. Los acontecimientos traumáticos supondrán una grieta o fuga por la que entren en escena otras maneras de vivir, acontecimientos insospechados. Las rupturas familiares se encontrarán en la base de ese tipo de acontecimientos que les permitirá la posibilidad de labrar una ideación del tiempo distinta a la que sus estructuras mentales y sociales les predisponen. En el caso de las mujeres, sobre todo las que proceden del mundo urbano, los conflictos de pareja serán los que las empujen a tomar la decisión de emigrar, no sin antes haber interiorizado un mundo interior basado en los ideales del amor romántico, una vida íntima, de ensoñación, que chocará con la realidad del maltrato cotidiano, los golpes, la infidelidad de sus parejas, la separación o el abandono de sus padres. En el caso de las mujeres provenientes del campo será sobre todo la falta de horizontes e incentivos lo que las hará emigrar. Los varones mientras tanto se quedarán en el país de origen, esperando de manera expectante cómo les va a las mujeres en su nuevo destino. Hasta que viajen a España sus vidas seguirán los mismos derroteros de desorientación personal, o incluso irán a peor que cuando las mujeres estaban con ellos. Es tal la soledad y el desconcierto que las provoca quedarse sin los lazos afectivos familiares que tendrán muchas dificultades para llegar a comprender los motivos de su salida cuando inicien la travesía a España. En cambio, las mujeres, decidieron no mirar hacia atrás por esa voluntad tan inquebrantable que las acompaña.

Tuve que salir, no me quedaba más remedio. Mis tías me dijeron que me lo pensara, que mi padre se podría poner enfermo. Pero yo les dije: ¿Y quién piensa en mí? Agarré mis cosas y me fui (Mujer 4). 


\section{EL AZOTE DEL RELOJ}

Cuando las mujeres estén en suelo español se darán cuenta de que nada tienen planificado. Ante ellas se abre lo imprevisible, el azar, y no llegan a percibir el suelo que las sustenta. Podríamos decir que esta consideración es lo propio que caracteriza a la misma condición de emigrante. De un día para otro dejan de tener una historia, un pasado. Sólo tienen un presente incierto, y un futuro aún más nebuloso. También dejan de tener un paisaje urbano y natural que hace mella en sus intenciones de seguir el viaje iniciado, ya que no se reconocen en la monocromía de los colores, la luz y el clima. El espacio profundiza la sensación destemporalizadora y angustiosa con la que viven la realidad en esos primeros momentos. A partir de ese instante procuran por todos los medios un marco que las proporcione la estabilidad perdida. Pero con lo que se encontrarán será con acontecimientos a los que no podrán hacer frente con los códigos culturales propios, como por ejemplo que el dinero presida las relaciones sociales, incluso con sus familiares más directos.

El imperio del dinero, y los nuevos latidos del tiempo, supondrán para ellas la necesidad de adquirir un nuevo aprendizaje. Las mujeres emigrantes ya instaladas en España, compatriotas o no, les irán preparando para que vayan interiorizando un tiempo acelerado del que ya no serán capaces de controlar, impelidas a una búsqueda constante de recursos para trabajar de manera continua y sin pausa desde los primeros momentos de su estancia en Madrid.

Me llevó a su casa, en el barrio de Entrevías. Fuimos en tren y me iba explicando que aquí había que correr. Corría para un lado, para otro. Trabajaba como externa, limpiando cuatro casas. Al tercer día de estar en su casa me encontró un trabajo. Me explicó cómo se trabajaba por horas, y los gastos que tendría que afrontar (Mujer 2).

Cuanto más hacía más me exigía (su jefa) (Mujer 2).

Esta frase sintetiza correctamente los primeros momentos de todas las mujeres cuando acceden a sus primeros empleos, que suelen ser la mayoría de las veces en el servicio doméstico. Estas exigencias, vividas no sin conflicto, pero finalmente aceptadas, tienen que ver con la idea madurada de que vienen a sufrir y a aceptar cualquier trabajo bajo cualquier condición.

Las mujeres tienen más dificultad que los varones para apropiarse de espacios más amplios que vayan más allá de aquellos que puedan proporcionar ventajas para conseguir un empleo. Las redes que construyen son una ventaja, pero también una desventaja, pues no les permiten salir a espacios más amplios. Si las mujeres se relacionaron sobre todo con las regiones morales de la ciudad por la urgencia de encontrar trabajo, los varones acceden a un empleo casi de manera inmediata gracias a las mujeres que los han reagrupado. La actividad laboral de los varones los permite conocer y profundizar el espacio, sobre todo la geografía física, lejos de los espacios domésticos a los que se ven forzadas las mujeres. Los varones empiezan a relacionarse y a arraigarse en el espacio gracias sobre todo a sus ocupaciones, rompiendo esquemas mentales que los permiten valorar poder viajar, disfrutar del conocimiento de lugares nuevos para ellos y apropiarse de espacios más amplios que en sus sociedades de origen, donde las barreras simbólicas y físicas eran tales que incluso les impedían conocer bien sus propias ciudades.

Los inmigrantes no viajan dentro de España o no salen a conocer, no hay eso de que viajas o esperas los festivos. Que tratas de vivir el día a día, o sea, de lo que hay (Varón 2). 
El trabajo para las mujeres, definitivamente, significa literalmente quedarse sin tiempo propio para ir a la búsqueda de mejores empleos, o para trabajar en varios sitios a la vez. Se las exige un ritmo tan trepidante en sus trabajos que quedan agotadas física, mental y emocionalmente. Tienen que adquirir el ritmo de trabajo a costa de amoldar sus cuerpos a los nuevos requerimientos temporales que les son impuestos. Además son innegociables. Tienes que comer deprisa y como puedas (Mujer 5).

Cuanto más hacen más les exigen. Como trabajan en sectores donde la proximidad entre empleador y empleada es máxima, lo laboral y lo personal se mezclan de tal manera que ambas dimensiones terminan por confundirse. No poder separar estos dos ámbitos hace que las relaciones laborales acaben convirtiéndose en prestaciones personales por parte del empresario, por un lado, y en favores por parte del trabajador por el otro. Apenas tienen tiempo para el ocio. Cuando libran están tan agotadas que lo único que les apetece es recluirse en el ámbito doméstico, realizar para sí las tareas propias de un ama de casa que ellas realizan para otros. Muchas de ellas no han ido nunca al cine a pesar de estar viviendo muchos años en Madrid.

El trabajo servirá a mujeres y varones inmigrantes para recuperar la estabilidad perdida, les proporcionará un estilo de vida y un tiempo asociado que irán interiorizando sin oportunidad de ser pensado ni reflexionado. Asumirán de forma escalonada un tiempo capitalista al que contribuirá la propia dinámica de la inmigración, marcando el inicio de la construcción de nuevas biografías. Se convertirán de este modo en inmigrantes, varones y mujeres sin un tiempo propio, instalados a marchas forzadas en un mundo de desconfianza, incomprensión e inseguridad. Las mujeres harán gala de una especial adaptación a las situaciones cambiantes que les obliga su nueva situación, especialmente la urgencia de encontrar empleo. Esta adaptación se hará en primer lugar modificando sus actitudes corporales para integrar y amoldar su cuerpo a los nuevos y veloces requerimientos productivos. La reconfiguración de sus movimientos corporales supondrá una nueva forma de apropiarse del espacio, al precio de afectar a su salud física y mental. La sucesión tan veloz con la que se suceden los acontecimientos y las exigencias laborales hace que no puedan ser asimilables y reflexionadas por falta de tiempo. La sociedad a su vez generará una falta de reconocimiento al poner toda la carga de las exigencias propias del espíritu capitalista exclusivamente sobre el individuo y no sobre el grupo, acentuando la sensación real de agotamiento físico y mental que provoca saberse los únicos responsables de sus propias existencias y labores.

Vivir es compartir y comunicar. Allí vives todos, y no como aquí, que cada uno es un mundo sin relación los unos con los otros (Mujer 5).

Se puede entender entonces que cuando ponen la música a todo volumen, no se trata de que no tengan consideración hacia los demás, sino que es una manera de dotar de sentido a ese momento, invitando y haciendo participe de la música a todo el vecindario. Se trata de un tiempo y un espacio creado entre todos y en el que todos se reconocen, tanto en el pasado, por ejemplo en las letras de las canciones, como en el presente, indicando un estado de ánimo, así como en el futuro, pues es una forma de decir que se reconocen juntos en ese acto insignificante y que se seguirán reconociendo. Existen multitud de actos cotidianos de los que está hecha la vida social y que son los auténticos circuitos por donde circula el sentido. Igualmente sucede con los olores, los ruidos, determinados espectáculos visuales o cualesquiera otros acontecimientos menudos. De su compresión y su interpretación dependerá la verdadera integración, una integración que pase por diferenciar 
claramente el nosotros del yo, que transcienda la integración como un mero proceso de individualización.

Ahorrar es muchas veces, muy a menudo, el trasfondo que hay detrás de la decisión de emigrar. La obsesión por el dinero conduce a la pérdida de los referentes biográficos, a seres sin memoria, sin horarios, sin historia y sin afectos, en definitiva, a la exclusión del grupo de pertenencia. El pasado tienen que aparcarlo para cumplir con su propósito migratorio, pues la emigración es inmigración de trabajo, adquiriendo todo su sentido mediante el sacrificio y el cálculo meramente basado en la consecución de dinero. Mujeres $\mathrm{y}$ varones emigrantes, si quieren trabajar y quieren integrarse, tienen que hacer como si olvidaran lo aprendido en sus sociedades de origen. "La emigración no debe verse sólo en términos de memoria y de nostalgia, donde la narrativa de origen tiene el efecto de desestabilizar el presente, sino también en términos de olvido de su pasado" (Kingman, 2005:472), con la correspondiente ventaja de adaptabilidad permanente a las rupturas espontáneas del curso rutinario de la vida.

El sistema capitalista necesita el tiempo pasado de los emigrantes, pero necesita aún más que este pasado sea negado, necesita imperiosamente que la memoria y sus marcos sociales no afloren a la superficie, ya que de lo contrario nos toparíamos con lo que hay de social en el tiempo, con la naturaleza temporal de la sociedad y la posibilidad de transformación y cambio. Vivir casi de manera exclusiva para ganar dinero tiene como efecto ideológico que la sociedad de por sentado y de manera inequívoca que el papel primordial de los emigrantes es el de trabajar. Los inmigrantes a su vez interiorizan la obligación de trabajar cada vez más y con más intensidad, con la consiguiente desestructuración personal y familiar. Se produce entonces, entre otras patologías, una exclusión difusa derivada de sus horarios intempestivos al no poder participar en actividades sociales comunes. En muchas ocasiones, a pesar de tener a sus amistades y familiares cerca, no pueden tener con ellos el contacto que ellos y ellas desearían.

La materia de la que está hecha la emigración es la incertidumbre: vivir un tiempo y un espacio que no son propios, y que además son impuestos. La vida les pasa. No son ni de aquí ni de allí. "Aquí", para las mujeres inmigrantes andinas, es no disponer de tiempo. "Allí", es tener tiempo de sobra. Esta contradicción tiene su reflejo, en primer lugar, en la queja que manifiestan las mujeres acerca del poco tiempo del que disponen en Madrid y, en segundo lugar, el amplio margen de tiempo del que disponían en sus ciudades de origen. La paradoja de esta aseveración no reside en la primera proposición, que es verdad, sino en la segunda, pues en sus sociedades no es que haya más o menos tiempo sino que el tiempo es, desde nuestra percepción europea, algo problemático por la lentitud de los procesos. La explicación habría que buscarla en los ritmos de las ciudades de donde vienen. Quito, y presumimos que también el resto de ciudades andinas, presenta muchos problemas para trasladarse de un lugar a otro, tanto por la deficiencia de su transporte público como por el alto grado de inseguridad ciudadana, que hace que la mayor parte de los ciudadanos abandonen precipitadamente el espacio público a unas determinadas horas. En Madrid, en cambio, se desplazan a muchos lugares de la ciudad con suma facilidad debido a la facilidad del transporte, ocupando, por tanto, también durante más tiempo la ciudad. Esta circunstancia que aparentemente debería de ser una ventaja para ellas, sin embargo se convierte en una queja generalizada cuando señalan que en Madrid les falta tiempo, y que en sus países el día tiene más de 24 horas. Esta impresión es obviamente contradictoria, pero sin embargo tiene una doble explicación: por un lado, la falta de ayuda de amistades y familiares, que hace que las energías se agoten, y, por el otro, la 
equiparación inconsciente entre el alto número de actividades, que una gran urbe moderna permite, y el tiempo invertidas en ellas, o dicho de otra manera, muchos desplazamientos equivalen a muchas horas que restan tiempo al reloj.

En sus ciudades, por el contrario, no son numerosos los desplazamientos, como tampoco son grandes las distancias que recorren, por lo que el resultado es disponer de mucho tiempo, y por tanto el tiempo suma, aunque luego exista un queja acerca de la lentitud en la que se desenvuelve la vida cotidiana, desde las grandes colas que se forman para hacer cualquier tipo de trámite hasta los intentos infructuosos para llevarlos a cabo. Estas gestiones infructuosas les obligan a volver a intentarlo de nuevo en otro momento con la ayuda de familiares o amistades, que a su vez facilitan la realización de otras tareas al mismo tiempo. A la escasez y la ineficiencia del transporte público, hay que añadir que los escasos desplazamientos de un lugar a otro de la ciudad obedecen a la poca necesidad de contactar con otros grupos sociales, más altos o más bajos en la jerarquía de la ciudad, circunscribiendo a sus espacios sociales de referencia todos los contactos que mantienen con el mundo social. Cuando emigren a Madrid, utilizarán la ventaja de esa forma de estar y moverse en los espacios reducidos, aprovechando las ventajas de saber que es en esos lugares justamente donde se encuentran los recursos disponibles para integrarse en la ciudad, recursos que en mucha ocasiones ni siquiera los nativos son capaces de descubrir. Por eso se mueven en los locutorios de los barrios, en las iglesias barriales, en los parques y en todos aquellos lugares populares, lo mismo que hacían en sus ciudades.

El "aquí" y el "allí" adquieren todo su sentido cuando las mujeres y los varones se plantean la idea del retorno a sus países. Las mujeres, al plantearse el retorno, muestran una ideación de su futuro de manera distinta a la de los varones. Muestran de nuevo más decisión que ellos acerca de las circunstancias que podrían motivar su retorno: quedarse sin trabajo, esperar y no tomar decisiones precipitadas hasta ver por dónde puede derivar la crisis económica, o que el destino o dios les proveerá en caso de dificultades. A los varones, por su parte, los paraliza la angustia, la ansiedad, no saber qué hacer en el caso de que regresaran, o simplemente y como dice uno de los varones:

Son tantas las posibilidades que abre un segundo, que se hace muy difícil poder manejar nuestro destino, por lo que es casi mejor no hacer nada (Varón 3).

\section{CONSIDERACIONES FINALES}

Si existen seres con historia y con un bagaje biográfico digno de ser contado por las peripecias y aventuras que han protagonizado, no cabe duda que son los emigrantes. Las vidas de los inmigrantes y sus trayectorias ocupan un lugar de honor para ser relatados, aunque la sociedad se empeñe en negarles su propia historia, estigmatizándolos y deshumanizándolos a través de su invisibilización, convirtiéndolos en seres sin pasado, o con un pasado sospechoso, arrogándose un tiempo y un espacio que pareciera privativo y único de grupos privilegiados, y por tanto, como si no existieran otras coordenadas espacio-temporales que las propias, en definitiva, atribuyéndose de manera exclusiva la única identidad posible, a costa de negársela a los demás. Una de las dificultades más penosas que lleva consigo la emigración es que no permite a los emigrantes pensar, ni pensarse a sí mismos, al no disponer de marcos espaciales y temporales apropiados, algo que afecta a sus oportunidades para actuar y decidir. El espacio y el tiempo de los emigrantes se parecen a veces al espacio y al tiempo de las instituciones totales, de las instituciones cerradas, pues con frecuencia no hay espacio para la fiesta, y por tanto no hay 
posibilidad de celebrar nada, incluidas las sorpresas, las experiencias, los acontecimientos inesperados.

En resumen, hay algo de paradójico, y este es el nudo gordiano al que nos vemos abocados como resultado de esta investigación, en el punto de partida y en el punto de llegada de mujeres y varones. Los varones construyen el relato de su vida de manera más individual, lo que les inclina a engendrar una estructura de carácter constantemente en recuperación. Las razones que alegan acerca de por qué han emigrado son construidas en la sociedad de destino, gracias a que la programación del tiempo ahora es posible, en contraposición a sus lugares de origen donde era más que problemático, permitiéndoles construir una narrativa merced a las obligaciones que les impone la nueva situación, finalizando el relato incompleto de sus trayectorias. Richard Sennett señala que "la rutina puede degradar, pero también componer una vida mediante la asunción de la responsabilidad individual" (Sennett, 2000:39). Por el contrario, las razones que alegan las mujeres acerca de los motivos de su emigración son las mismas que cuando estaban en sus países de origen, lo que demuestra que son más hábiles que los varones en el aprendizaje del tiempo secuenciado, relacionando el pasado, el presente y el futuro de manera más lineal, aunque paguen por ello una merma de su libertad en términos de tiempo y repitan de nuevo en las sociedades de acogida aquellas condiciones sociales que las empujaron a emigrar, como la rutina y la falta de horizontes de bienestar debido a la carga excesiva de trabajo en la sociedad de destino.

El concepto de tiempo que hemos manejado en esta investigación no ha sido ni el tiempo de la sucesión, ni tampoco exclusivamente el tiempo intencional, sino un tiempo único donde convergen estas dos dimensiones. De las diversas metáforas que se generan en el lenguaje sobre el tiempo, y que hacen posible designar lo temporal, nos hemos centrado sobre todo en el tiempo como un horizonte temporal, el tiempo que se sitúa en el plano cognitivo-moral de la intencionalidad, y que permite contemplar en el presente el panorama de lo ocurrido y conjeturar el porvenir. Esta perspectiva sobre el tiempo necesita más que otras de la memoria y la reflexión, materiales que han servido a los emigrantes para reconstruir sus nuevas biografías en una sociedad que no les ha visto nacer ni crecer. La inmigración conlleva estos dos elementos y sin ellos no se puede comprender ni explicar este fenómeno desde una sociología crítica y reflexiva.

Son precisamente los laberintos del tiempo en el que nace y se desarrolla la experiencia emigrante los territorios que este texto ha querido explorar. Espero al menos haber mostrado que el tiempo social constituye un territorio clave para comprendernos a nosotros y a los demás, un territorio poco explorado que permanece abierto para la investigación colectiva en el futuro.

\section{BIBLIOGRAFÍA}

ALVARÉZ URÍA, F. y VARELA, J. (2004). Sociología, capitalismo y democracia. Madrid, Morata.

CASTEL, R. (1995), "De la exclusión como estado a la vulnerabilidad como proceso". Archipiélago, $\mathrm{n}^{\circ}$ 21, pp. 27-36.

CASTORIADIS, C. (1989), La institución imaginaria de la sociedad, Vol. 2, El imaginario, lo social y la institución. Barcelona, Tusquets.

DURHHEIM, E. (1992), Las formas elementales de la vida religiosa. Madrid, Akal. 
IGLESIA USSEL, J. (2006), La dimensión social del tiempo, Madrid, Real Academia de Ciencias Morales y Políticas.

NORBERT, E. (1989), Sobre el tiempo. México, FCE.

PAZOS, A. (2004), 'Narrativa y subjetividad. A propósito de Lisa, una 'niña española'. Revista de Antropología Social, ${ }^{\circ} 13$ 49-96.

RAMOS, R. (1997), "La ciencia social en busca del tiempo". Revista Internacional de Sociología (RIS), n $\mathrm{n}^{\mathrm{1}}$ 18, pp. 11-37.

RAMOS, R. (1992), Tiempo y Sociedad, No 129, Madrid, CIS- Siglo XXI.

SENNETT, R. (2000), La corrosión del carácter, Barcelona, Anagrama.

SENNETT, R. (1975), Vida urbana e identidad personal, Barcelona, Península.

SOTELO, I. (2010), El estado social. Antecedentes, origen, desarrollo y declive, Madrid, Trotta.

TODOROV, T. (2003), La conquista de América. El problema del otro, Buenos Aires, Siglo XXI.

WEBER, M. (1987), Economía y sociedad, México, FCE.

\section{Breve currículo:}

\section{Juan José Ruiz Blázquez}

Doctor en Sociología, Universidad Complutense de Madrid. Colaborador Honorífico del Departamento de Sociología IV. Sus intereses de investigación giran en torno a la sociología histórica, el tiempo y los procesos de subjetivación, así como la metodología cualitativa en investigación social. Ha trabajado como sociólogo en la Consejería de Inmigración de la Comunidad de Madrid, así como Técnico de Empleo y Desarrollo Local en la Sierra Norte de Madrid. También ha ejercido labores de Orientación para el empleo y el autoempleo en el Ayuntamiento de Madrid, la Universidad Complutense de Madrid y en el Colegio de Politólogos y Sociólogos de Madrid. Actualmente el gobierno ecuatoriano le ha concedido una beca PROMETEO en el Instituto de Altos Estudios Nacionales de Ecuador (IAEN) como científico social. 